\title{
INTESTINAL MICROORGANISMS AFTER PROBIOTIC TREATMENT IN RAT
}

\author{
A. Mustari*, N. Ahmad, S. Saha and P. Paul \\ Department of Physiology, Faculty of Veterinary Science, Bangladesh Agricultural University, \\ Mymensingh-2202, Bangladesh.
}

\begin{abstract}
The study was carried out to know the effect of probiotics (Bio-Top ${ }^{\circledR}$, Curd) supplementation on intestinal microorganisms in rats (Rattus norvegicus) during the period of 01 March to 20 April 2011. A total of twelve (12), one month old rats were randomly divided into 3 experimental groups: A, B and C, with 04 rats in each group. Group C was fed with commercial rat pellet $(20 \mathrm{gm} / \mathrm{rat})$ without supplementation of probiotics (control), group A was fed with commercial ration $(20 \mathrm{gm} / \mathrm{rat}) \mathrm{with}$ addition natural probiotic (Curd) and group B was fed with commercial ration ( $20 \mathrm{gm} / \mathrm{rat})$ with the addition of commercial probiotic $\left(\right.$ Bio-Top $\left.^{\circledR}\right)$ feed for 7 weeks. Feed and water were supplied ad libitum. The result showed that intestinal bacterial population changed in probiotics treated groups compared to control group. Bacillus spp. was isolated from Bio-Top ${ }^{\circledR}$, Curd and Probiotic treated rats. Whereas E. coli was present in control rats, indicating environmental contamination which is hazardous for public health. The study suggests that probiotics supplementation helps in maintaining normal haematobiochemical values and beneficial gut microbes.
\end{abstract}

Keywords: Curd, Probiotic, Rat, Bacillus spp., E. coli

\section{INTRODUCTION}

The intestinal microflora constitutes a metabolically active microbial environment, dominated by a relatively low diversity of genera, which, in the gut of healthy individuals, exist as part of a stable community. Under normal circumstances, these resident gut bacteria cause neither pathogenesis nor inflammation in the host, but instead contribute to health maintenance, by forming a barrier layer against colonization by pathogens and by aiding in nutrient digestion and assimilation (Fuller, 1989). In addition, the resident intestinal microflora plays other important physiological roles in health maintenance: deconjugating potentially damaging oxidative metabolites and toxins in the gut; degrading potentially allergenic food proteins; regulating cholesterol and triglyceride uptake; increasing vitamin biosynthesis; and providing immunosurveillance signals to limit intestinal-tract inflammation. Thus, a stable, properly functioning and active intestinal-tract microflora is essential to the continuance of health. (Lee and Salminen, 1995)

The probiotic approach, therefore, advocates the supplementation of food products with live microbial additions, whilst a prebiotic would be a component of diet that has a selective fermentation by indigenous bacterial species. Both approaches have the common objective of growth promotion through beneficial bacterial microorganisms. One further approach is the combination of probiotic and prebiotic as 'symbiotic', i.e.use of the live microbes in feed additive to a substrate that promote its growth (Singh and Chauhan, 2004)

The residues of antibiotics in milk, egg or meat are the cause of several deleterious effects in man including allergy and resistance of infections. Such problems will get reduced after the use of probiotics particularly in the form of cow curd (Nautiyal, 2002). The aim of this research was to evaluate the effect of probiotics on the intestinal bacterial population.

\section{MATERIALS AND METHODS}

\section{Study site and period}

The study was conducted in the Bacteriology Laboratory of the Department of Microbiology and Hygiene, Faculty of Veterinary Science, Bangladesh Agricultural University (BAU), Mymensingh-2202, Bangladesh. The whole experiment was conducted during the period of 01 March to 20 April 2011.

*Corresponding e-mail address: afrinadvm@gmail.com 


\section{A. Mustari and others}

\section{Experimental rats and probiotics}

A total of 12, one month aged male rats (Rattus norvegicus) were used. The rats were purchased from ICDDR'B, Dhaka. They were treated with natural probiotic (Curd) and commercial probiotic Bio-Top ${ }^{\circledR}$ which contains the bacterial strains of Bacillus subtilis and Bacillus licheniformis. After 7 weeks of treatment, the samples were taken from curd, Bio-Top ${ }^{\circledR}$, cecum and colon of experimental animal.

\section{Experimental design}

The whole experiment is composed of isolation of the bacteria from probiotics and samples collected from cecum and colon of treated rats and identification of Bacillus spp. by cultural and morphological characteristics. Carbohydrate fermentation tests were also used to confirm the isolated organisms.

\section{Collection of samples}

The samples comprising curd, Bio-Top, content of cecum and colon were collected with proper aseptic measures. Immediately after collection, the samples were put into sterile test tubes and carried to the laboratory of the Department of Microbiology and Hygiene for inoculation into culture media.

\section{Culture of Bacteria}

Primary growths of bacteria of each collected sample were performed in nutrient broth (NB). Individual samples were then subjected to Gram's staining to ascertain the different types (morphology) of organism present in the culture. Each incubated broth sample was then streaked onto nutrient agar (NA), blood agar (BA) plates separately as to obtain individual colony (Cheesbrough, 2006).

From individual colony subculture were grown on BA, NA and Eosin methylene blue (EMB) agar media for obtaining pure culture of the isolated organisms. After determining cultural character, these pure cultures of the organisms were subjected to staining and morphological examination for identification of organisms. (Cheesbrough, 2006).

\section{Biochemical tests}

Isolated organisms with specific characteristic on NA, BA, and EMB agar were subjected to biochemical tests. Standard methods were followed to conduct this test according to the procedure described by (Cowan, 1985).

\section{Catalase test}

This test was used to differentiate bacteria, which produce the enzyme catalase, such as Bacillus, from that noncatalase one such as, Lactobacillus. To perform this test, a good growth culture of test organism was smeared in a sterile wooden stick or glass rod and was immersed into the $\mathrm{H}_{2} \mathrm{O}_{2}$ solution. In case bubbles of oxygen are released, the organisms are considered catalase producer (Carter, 1986).

\section{RESULTS AND DISCUSSION}

\section{Cultural examinations}

\section{Nutrient agar}

Nutrient agar plates streaked separately with the samples indicated the growth of bacteria after 24 hours incubation at $37^{0} \mathrm{C}$ aerobically. Production of white colonies indicates Bacillus spp. The results of the cultural examination on NA are similar with the report of Gordon (1964), Cheesbrough (2006).

\section{Eosin Methylene Blue (EMB) agar}

After overnight incubation there was no metallic sheen on EMB agar, indicate Bacillus spp that did not grow on EMB agar. But samples from untreated groups show metallic sheen on EMB agar indicates E. coli. The findings are in agreement with the statement of Buxton and Fraser (1977). 


\section{Blood agar}

After overnight incubation at $37^{\circ} \mathrm{C}$ on blood agar there was hemolysis indicates presence of Bacillus spp. From the sample collected from curd, Bio-Top ${ }^{\circledR}$, cecum and colon of treated rats. But samples collected from control group did not show any hemolysis which are in agreement of the earlier report of Cheesbrough (2006).

\section{Gram's staining}

In Gram's staining under microscope, bacterial colony collected from curd, Bio-Top, treated samples appeared as Gram positive, rod shape indicates Bacillus spp. On the other hand colony from untreated group appeared as Gram negative, pink color, small rod shaped, arranged in single or paired indicates $E$. coli. These finding are more or less similar with the findings of Freeman (1985) and Honda et al. (1982).

\section{Carbohydrate fermentation tests}

Acid production was indicated by the color change from reddish to yellow and gas production was noted by the appearance of gas bubbles in the inverted Durham's tubes. Colony inoculated from curd, Bio-Top ${ }^{\circledR}$ and treated samples produce only acid indicates Bacillus spp. But colony from untreated samples produce acid and gas indicates E. coli.

The results of this investigation indicated that the samples contain both Gram positive and Gram negative bacteria.

The results of this investigation indicated that the samples contained both Gram positive and Gram negative bacteria. Samples collected from curd, Bio- Top ${ }^{\circledR}$, and probiotic treated groups contained Bacillus spp. And samples of control group contained E. coli. So from above findings, it can be concluded that bacteria Bacillus spp. produces the beneficial effect on rats by improving enzymatic activity, inhibiting growth of pathogenic organisms, enhancing growth and regulating immunity.

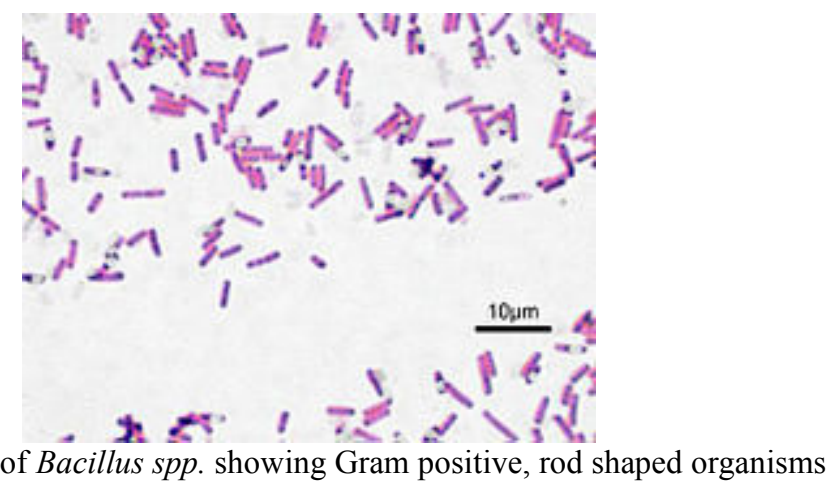

\section{ACKNOWLEDGEMENT}

The authors would like to acknowledge Ministry of Science and Information \& Communication Technology, Government of People's Republic of Bangladesh, for financial support.

\section{REFERENCES}

1. Buxton A and Fraser G (1977). Animal Microbiology. Vol. 1. E. Coli, Balckwell Scientific Publications, Oxford, London, Edinburg, Melbourne. pp. 94-102.

2. Carter GR (1986). Essentials of Veterinary Bacteriology and Mycology. $3^{\text {rd }}$ edn. Lea and Febiger, 60 Washington square, Philadelphia, Washington D C.

3. Cheesbrough M (2006). District Laboratory Practice in Tropical Countries. Part 2. 2nd edn. Cambridge University Press, New York. USA. pp: 45-62. 
4. Cowan ST (1985). Cowan and Steel's Manual for Identification of Medical Bacteria. 2nd edition. Cambridge University press, Cambridge, London. pp. 138-139.

5. Freeman BA (1985). Burrows Textbook of Microbiology. $22^{\text {nd }}$ edn. In: W. B. Saunders company, Philadelphia, London, Toronto, Mexici city, Rio de Janerio, Sydney, Tokyo, pp. 464-475.

6. Fuller R (1989). Probiotics in man and animals. The Journal of Applied Bacteriology 5 365-378.

7. Gordon MA (1964). The Genus Dermatophilus. Journal of Bacteriology 88:509-522.

8. Honda T, Arita M, Takela Y and Miwatani T (1982). Further evaluation of the Biken Test (Modified Eleck Test) for deletion of enterotoxigenic $E$. coli producing heat table enterotoxin and application of the test to sampling of heat stable enterotoxin. Journal of Clinical Microbiology 16:60-62.

9. Lee YK, Salminen S (1995). The coming of age of probiotics. Trends in Food Science \& Technology 6: 241244.

10. Nautiyal CS (2002). Cow's milk a novel source of microbial wealth. In: Gay Ka Dudh Amrit Hai. Pp. 8698. Love4cow Trust, New Delhi.

11. Singh BP and Chauhan RS (2004). Role of probiotics in control of poultry diseases. Pashudhan 17 (8):3. 